\title{
Utilização de marcadores moleculares RAPD e EST's SSR para estudo da variabilidade genética em cana-de-açúcar ${ }^{1}$
}

\author{
Use of molecular markers RAPD, and ESTs SSR to study genetic variability in \\ sugarcane
}

\author{
João Andrade Dutra Filho ${ }^{2 *}$, Luciane Vilela Resende ${ }^{3}$, Gerson Quirino Bastos ${ }^{4}$, Djalma Euzébio Simões Neto ${ }^{4}$ e \\ Paulo Rocha Machado ${ }^{4}$
}

\begin{abstract}
RESUMO - Marcadores moleculares dos tipos RAPD e EST's SSR foram utilizados como ferramentas para avaliar a variabilidade bem como estimar a divergência genética entre variedades comerciais e clones de cana-de-açúcar oriundos via autofecundação. Vinte e três genótipos foram utilizados neste estudo oriundos do Programa de Melhoramento Genético da Cana-de-açúcar da Rede Interuniversitária para o Desenvolvimento do Setor Sucroalcooleiro (PMGCA/RIDESA). A extração do DNA genômico seguiu a metodologia CTAB com modificações para cana-de-açúcar. Foram utilizados 11 oligonucleotídeos RAPD da operon Technologies e 7 EST's SRR obtidos através de uma extensa revisão de literatura. As análises da divergência genética foram realizadas com o auxílio do Programa GENES. Os marcadores RAPD detectaram um alto grau de polimorfismo genético, produzindo 61 bandas, das quais 58 foram polimórficas. Os marcadores EST's SSR amplificaram 38 alelos, sendo 34 polimórficos. Havendo a formação de três grupos, com a população estudada. A maior parte da variação genética foi mantida dentro das progênies, evidenciando a ocorrência de um alto grau de variabilidade genética entre os genótipos de cada progênie para fins de melhoramento. Através da divergência genética estimada foi possível identificar parentais divergentes para trabalhos de hibridação, visando a obtenção de clones superiores com caracteres de interesse à agroindústria canavieira. Os marcadores molecuares RAPD e EST's SSR foram igualmente eficientes para estimar a variabilidade genética nos genótipos testados e elaborar os cruzamentos a serem realizados nos programas de melhoramento.
\end{abstract}

Palavras-chave: Cana-de-açúcar. Melhoramento Vegetal. Moléculas-modelos.

\begin{abstract}
Molecular markers of the type RAPD and ESTs SSR were used as tools to evaluate the variability, and estimate the genetic divergence between commercial varieties and sugarcane clones from self-pollination. Twenty-three genotypes from the Program for the Genetic Improvement of Sugarcane of the Interuniversity Network for the Development of the Sugaralcohol Sector (PMGCA/RIDESA), were used in this study. The extraction of genomic DNA followed CTAB methodology, with modifications being made for sugarcane. Eleven RAPD oligonucleotides, obtained from Operon Technologies, and 7 ESTs SRR, found after an extensive review of the literature, were used. Analyses of genetic diversity were carried out using the GENES software. The RAPD markers detected a high degree of genetic polymorphism, producing 61 bands, of which 58 were polymorphic. The ESTs SSR markers amplified 38 alleles, 34 being polymorphic. Three groups being formed with the population studied. Most of the genetic variation was maintained among progeny, indicating the occurrence, for purposes of breeding, of a high degree of genetic variability among the genotypes of each progeny. Through estimated genetic divergence, it was possible to identify divergent parent plants, which could be used in hybridization in order to obtain superior clones with characteristics of interest to the sugarcane industry. The molecular markers RAPD and ESTs SSR were equally efficient in estimating the genetic variability in the genotypes tested, and in preparing crossbreeds to be used in breeding programs.
\end{abstract}

Key words: Sugarcane. Plant Breeding. Molecular-models.

\footnotetext{
* Autor para correspondência

${ }^{1}$ Recebido para publicação em 06/09/2011; aprovado em 25/06/2012

Parte da Dissertação de Mestrado do primeiro autor apresentada ao Programa de Pós-Graduação em Agronomia (Melhoramento Genético de Plantas) da Universidade Federal Rural de Pernambuco

${ }^{2}$ Universidade Federal Rural de Pernambuco, Brasil, filho-dutra@ig.com.br

${ }^{3}$ Universidade Federal de Lavras, Brasil, luciane.vilela@dag.ufla.br

${ }^{4}$ Universidade Federal Rural de Pernambuco, Brasil, bastosgq@hotmail.com, desn@oi.com.br, machadop_rocha@yahoo.com.br
} 


\section{INTRODUÇÃO}

A cana-de-açúcar (Saccharum spp) é uma espécie bem complexa no que se refere à sua natureza genética, devido à sua base citológica e aos diferentes níveis de ploidia. Em programas de melhoramento com essa espécie, os estudos visando a estimação da variabilidade genética são de extrema importância, não apenas por auxiliar nos trabalhos de seleção mas também em função da degenerescência varietal que ocorre com o passar do tempo nas variedades comerciais, afetando seus rendimentos agrícola e industrial (STUPIELLO, 2002). Por este motivo, a retroalimentação de novas variedades que atendam as demandas agroindustriais deve ser continuamente mantida nos programas de melhoramento para substituição das obsoletas ou daquelas que já apresentam o problema em questão.

No Brasil, o Estado de Pernambuco se destaca como um dos tradicionais produtores de cana-de-açúcar da Região Nordeste com uma produção de aproximadamente 18,5 milhões de toneladas (COMPANHIA NACIONAL DE ABASTECIMENTO, 2012).

Em cana-de-açúcar, a variabilidade genética para a seleção de novos clones para exploração comercial é obtida através da realização de cruzamentos entre variedades comerciais e pré-comerciais que apresentem em sua constituição genes relacionados a caracteres de interesse. Para explorar eficientemente este processo devem-se efetuar hibridações entre genitores divergentes (MATSUOKA; GARCIA; ARIZONO, 2005).

A divergência genética pode ser estimada com base em métodos preditivos a partir de marcadores agronômicos, bioquímicos, morfológicos e moleculares (SHIMOYA et $a l .$, 2002). Mesmo tendo grande utilização em programas de melhoramento, os marcadores agronômicos apresentam a limitação de serem facilmente influenciados pelo ambiente (SALLA et al., 2002).

Os marcadores moleculares, em contrapartida, apresentam a vantagem de representarem o genótipo proveniente de um grande número de marcadores agronômicos e morfológicos (WUNSCH; HORMAZA, 2002). Além disso, aceleram a obtenção de genótipos desejáveis e podem estar ligados a locos que determinam características de interesse, não sendo influenciado por variações ambientais (FUGANTI et al., 2004). Para Leal et al. (2010), os marcadores moleculares RAPD e SSR estão entre os mais utilizados para determinação da divergência genética.

A técnica do polimorfismo de DNA amplificado ao acaso (RAPD) é de baixo custo e fácil execução. Consiste de iniciadores arbitrários e não dependem do sequenciamento prévio do genoma da espécie na qual vai ser aplicado. A grande vantagem dessa técnica seria a rapidez na obtenção dos resultados (CAIXETA et al., 2006). Já os iniciadores EST'S SSR são uma classe funcional de marcadores moleculares baseados em sequências simples repetidas. Estão ligados a locos que determinam características de interesse, apresentam o caráter co-dominante, podendo diferenciar os homozigotos dos heterozigotos formando locos genéticos altamente polimórficos (FERREIRA; GRATTAPAGLIA, 1998). A utilização conjunta destes dois tipos de marcadores cada um amplificando, quanto ao seu potencial, regiões específicas, contribuirá para uma maior cobertura do genoma e também para maior consistência nos resultados relativos a similaridade ou divergência genética interpopulacionais.

Neste trabalho, os marcadores dos tipos RAPD e EST's SSR foram utilizados visando avaliar a variabilidade genética entre e dentro de progênies elites de cana-deaçúcar bem como estimar a divergência genética entre três variedades comerciais e 20 clones oriundos via autofecundação.

\section{MATERIAL E MÉTODOS}

Três populações (progênies) oriundas via autofecundação com três variedades comerciais foram utilizadas neste estudo: seis genótipos obtidos da variedade RB867515, sete obtidos da RB943365 e 7 obtidos da RB863129 (Tabela 1). Todos os cruzamentos gerados pelo Programa de Melhoramento Genético da Cana-de-açúcar da RIDESA (Rede Interuniversitária para o Desenvolvimento do Setor Sucroalcooleiro), na Estação de Floração e Cruzamento de Devaneio, Amaraji, PE.

Os genótipos foram selecionados em campo na fase T1 cana soca através da seleção massal, baseando-se nos seguintes descritores, recomendados pelo PMGCA/ UFRPE/RIDESA.

A extração de DNA e as reações de amplificação seguiram o protocolo descrito por Nienhuis et al. (1995) com modificações para cana-de-açúcar. Foram utilizados 11 marcadores RAPD (Random Amplified Polymorphic DNA) da Operon Technologies: OPAL 09, OPAN 20, OPAX 02, OPAX 09, OPAX 10, OPAX 11, OPAX 12, OPAX 16, OPAX 17, OPAX 18 e OPAX 19.

Para os marcadores RAPD, as reações de amplificação tiveram volume final de $12,01 \mu \mathrm{l}$, contendo: 5,45 $\mu$ l de água, $2,25 \mu 1$ de DNA $\left(10\right.$ ng. $\left.\mathrm{ml}^{-1}\right)$, $0,66 \mu \mathrm{l}$ de dNTP $(50 \mu \mathrm{M}$, incluir o fabricante), $2,25 \mu \mathrm{l}$ de cada oligonucleotídeo $(0,4 \mu \mathrm{M}), 1,0 \mu \mathrm{l}$ de tampão de reação $10 \mathrm{X}$ e 0,4 unidades da enzima Taq polimerase (invitrogen). 
Tabela 1 - Identificação das três populações de cana-de-açúcar, genitores e caracteres morfológicos considerados no processo de seleção na fase T1 do PMGCA/UFRPE/RIDESA

\begin{tabular}{|c|c|c|c|c|c|c|}
\hline Genótipos & Genitores & $\mathrm{Pf}$ & $\mathrm{Vc}$ & $\mathrm{Hc}$ & $\mathrm{T}$ & $\mathrm{F}$ \\
\hline 1. RB867515 & RB72454 X? & Médio & Rápido & Ereto & Eventual & Eventual \\
\hline UFRPE06-01 & Auto. RB867515 & Baixo & Rápido & Ereto & Frequente & Eventual \\
\hline UFRPE06-02 & Auto. RB867515 & Baixo & Regular & Ereto & Eventual & Médio \\
\hline UFRPE06-03 & Auto. RB867515 & Médio & Regular & Ereto & Eventual & Eventual \\
\hline UFRPE06-04 & Auto. RB867515 & Médio & Regular & Ereto & Eventual & Eventual \\
\hline UFRPE06-05 & Auto. RB867515 & Baixo & Rápido & S.D & Raro & Raro \\
\hline UFRPE06-06 & Auto. RB867515 & Médio & Rápido & S.D & Eventual & Eventual \\
\hline 2. RB943365 & ROC3 X RB83100 & Médio & Regular & Ereto & Raro & Raro \\
\hline UFRPE06-07 & Auto. RB943365 & Médio & Regular & Ereto & Raro & Eventual \\
\hline UFRPE06-08 & Auto. RB943365 & Médio & Regular & Ereto & Raro & Raro \\
\hline UFRPE06-09 & Auto. RB943365 & Médio & Regular & Ereto & Raro & Raro \\
\hline UFRPE06-10 & Auto. RB943365 & Médio & Regular & S.D & Raro & Raro \\
\hline UFRPE06-11 & Auto. RB943365 & Baixo & Lento & S.D & Raro & Raro \\
\hline UFRPE06-12 & Auto. RB943365 & Alto & Rápido & S.D & Raro & Raro \\
\hline UFRPE06-13 & Auto. RB943365 & Alto & Lento & S.D & Raro & Eventual \\
\hline 3. RB863129 & RB763411 X? & Médio & Regular & S.D & Raro & Eventual \\
\hline UFRPE06-14 & Auto. RB863129 & Médio & Regular & S.D & Raro & Eventual \\
\hline UFRPE06-15 & Auto. RB863129 & Médio & Regular & S.D & Raro & Eventual \\
\hline UFRPE06-16 & Auto. RB863129 & Médio & Regular & S.D & Raro & Raro \\
\hline UFRPE06-17 & Auto. RB863129 & Alto & Regular & S.D & Raro & Eventual \\
\hline UFRPE06-18 & Auto. RB863129 & Alto & Regular & S.D & Eventual & Raro \\
\hline UFRPE06-19 & Auto. RB863129 & Alto & Rápido & Ereto & Raro & Ausente \\
\hline UFRPE06-20 & Auto. RB863129 & Médio & Regular & S.D & Raro & Eventual \\
\hline Genótipos & Genitores & $\mathrm{Ch}$ & $\mathrm{D}$ & Ts & $\mathrm{F}$ & Esc \\
\hline 1. RB867515 & RB72454 X? & Médio & Média & Alto & Resistente & Tolerante \\
\hline UFRPE06-01 & Auto. RB867515 & Pouco & Média & Alto & Resistente & Tolerante \\
\hline UFRPE06-02 & Auto. RB867515 & Ausente & Média & Alto & Resistente & Tolerante \\
\hline UFRPE06-03 & Auto. RB867515 & Médio & Média & Alto & Resistente & Tolerante \\
\hline UFRPE06-04 & Auto. RB867515 & Médio & Ausente & Alto & Resistente & Tolerante \\
\hline UFRPE06-05 & Auto. RB867515 & Médio & Média & Alto & Tolerante & Tolerante \\
\hline UFRPE06-06 & Auto. RB867515 & Médio & Difícil & Médio & Resistente & Resistente \\
\hline 2. RB943365 & ROC3 X RB83100 & Ausente & Fácil & Alto & Tolerante & Resistente \\
\hline UFRPE06-07 & Auto. RB943365 & Ausente & Fácil & Alto & Tolerante & Resistente \\
\hline UFRPE06-08 & Auto. RB943365 & Ausente & Fácil & Alto & Tolerante & Resistente \\
\hline UFRPE06-09 & Auto. RB943365 & Ausente & Fácil & Alto & Tolerante & Tolerante \\
\hline UFRPE06-10 & Auto. RB943365 & Ausente & Fácil & Alto & Tolerante & Resistente \\
\hline UFRPE06-11 & Auto. RB943365 & Médio & Fácil & Alto & Tolerante & Tolerante \\
\hline UFRPE06-12 & Auto. RB943365 & Médio & Média & Alto & Tolerante & Resistente \\
\hline UFRPE06-13 & Auto. RB943365 & Médio & Média & Alto & Tolerante & Resistente \\
\hline 3. RB863129 & RB763411 X? & Pouco & Fácil & Médio & Tolerante & Resistente \\
\hline
\end{tabular}


Continuação da Tabela 1

\begin{tabular}{lllcccc}
\hline UFRPE06-14 & Auto. RB863129 & Pouco & Fácil & Médio & Tolerante & Resistente \\
UFRPE06-15 & Auto. RB863129 & Pouco & Média & Médio & Tolerante & Resistente \\
UFRPE06-16 & Auto. RB863129 & Pouco & Média & Médio & Tolerante & Resistente \\
UFRPE06-17 & Auto. RB863129 & Pouco & Fácil & Médio & Tolerante & Tolerante \\
UFRPE06-18 & Auto. RB863129 & Médio & Média & Médio & Tolerante & Tolerante \\
UFRPE06-19 & Auto. RB863129 & Pouco & Fácil & Alto & Resistente & Resistente \\
UFRPE06-20 & Auto. RB863129 & Médio & Média & Médio & Resistente & Tolerante \\
\hline
\end{tabular}

Nota: $\mathrm{Pf}=$ Perfilhamento, $\mathrm{Vc}=$ Velocidade de crescimento, $\mathrm{Hc}=$ Hábito de crescimento, $\mathrm{T}=$ Tombamento, $\mathrm{F}=\mathrm{Florescimento}, \mathrm{Ch}=\mathrm{Chochamento}$, $\mathrm{D}=$ Despalha, $\mathrm{Ts}=$ Teor de sacarose, $\mathrm{F}=$ Ferrugem, Esc $=$ Escaldadura das folhas, $\mathrm{S} . \mathrm{D}=$ Semi-Decumbente

As reações foram amplificadas em termociclador Eppendorf Master Cycler Gradiente 5331. A amplificação foi seguida por 40 ciclos, com desnaturação inicial a $94^{\circ} \mathrm{C} / 5 \mathrm{~min}$ e cada ciclo com $94^{\circ} \mathrm{C} / 2 \mathrm{~min}, 37^{\circ} \mathrm{C} / 15$ segundos e $72^{\circ} \mathrm{C} / 1 \mathrm{~min}$, respectivamente para denaturação, anelamento e extensão, e uma extensão final a $72^{\circ} \mathrm{C} / 5$ minutos.

A separação dos produtos amplificados foi realizada em eletroforese horizontal a 50 volts, durante 2 horas. Os produtos foram visualizados em gel de agarose $(1 \%)$ corado com Brometo de etídio $\left(0,5 \mu \mathrm{g} \mathrm{ml}^{-1}\right)$ e fotodocumentados sob luz ultravioleta com câmara fotográfica EDA - 290 (Kodak).

Os oligonucleotídeos dos EST'S SSR usados neste trabalho foram desenvolvidos por Pinto et al. (2004). As reações de amplificação tiveram volume final de 12,01 $\mu 1$, contendo: 5,45 $\mu 1$ de água, 2,25 $\mu 1$ de DNA (10 ng.ml $\left.{ }^{-1}\right), 0,66 \mu 1$ de dNTP $(50 \mu \mathrm{M}), 2,25 \mu 1$ de cada par de oligonucleotídeo $(0,4 \mu \mathrm{M}), 1,0 \mu \mathrm{l}$ de tampão de reação $10 \mathrm{X}$ e 0,4 unidades da enzima Taq polimerase.

As reações foram amplificadas em termociclador Eppendorf Master Cycler Gradiente 5331. A amplificação foi seguida por 40 ciclos, com desnaturação inicial a $94{ }^{\circ} \mathrm{C} / 5 \mathrm{~min}$ e cada ciclo com $94{ }^{\circ} \mathrm{C} / 2 \mathrm{~min}$, $37{ }^{\circ} \mathrm{C} / 15$ segundos e $72{ }^{\circ} \mathrm{C} / 1 \mathrm{~min}$, respectivamente para desnaturação, anelamento e extensão, e uma extensão final a $72^{\circ} \mathrm{C} / 5$ minutos.

A separação dos produtos amplificados foi realizada em eletroforese vertical a 130 volts, durante 2 horas em gel de poliacrilamida desnaturante ( $8 \%$ ). Os produtos de amplificação foram corados com Nitrato de prata e fotodocumentados em câmara fotográfica EDA - 290 (Kodak).

Os marcadores moleculares foram analisados quanto a presença (1) ou ausência (0) de bandas, construindo-se uma matriz binária. A distribuição da variabilidade genética entre e dentro de progênies foi avaliada através da Análise Molecular de Variância (AMOVA), de acordo com Excoffier et al. (1992). As estimativas da divergência genética entre os genótipos foram obtidas por meio do complemento aritmético do coeficiente de Jaccard e para construir o dendrograma utilizou-se o método hierárquico do tipo UPGMA (Unweighted Pair Group Method Using Arithmetical Averages). Para verificar a concordância entre os valores originais de dissimilaridade e aqueles representados no dendrograma efetuou-se o cálculo do coeficiente de correlação cofenético segundo Sokal e Rohlf (1962). Os marcadores EST's SSR foram considerados como marcadores dominantes, podendo, neste caso, utilizar o coeficiente de Jaccard, conforme Amorim et al. (2008). As análises genético-estatísticas foram realizadas com o auxílio do programa Genes (CRUZ, 2006).

\section{RESULTADOS E DISCUSSÃO}

Os marcadores RAPD utilizados no presente trabalho geraram alto grau de polimorfismo genético nos genótipos avaliados. O número total de bandas produzidas foi de 61 , que representa $100 \%$ dos fragmentos amplificados (Tabela 2). O número total de bandas polimórficas foi de $58(95,08 \%)$, enquanto que o número de bandas monomórficas foi três $(4,92 \%)$.

O oligonucleotídeo OPAX 19 gerou o maior número de bandas (nove), todas elas polimórficas (100\%). Os oligonucleotídeos OPAX12, OPAX16, OPAX16, OPAX17, OPAN20, OPAL09, e OPAX02 também apresentaram $100 \%$ de polimorfismo, com um total de 8 ; $7 ; 6 ; 5 ; 5 ; 5$, e 1 bandas respectivamente, sendo esses oito os marcadores mais polimórficos.

O percentual de polimorfismo detectado com os marcadores RAPD neste trabalho foi semelhante ao obtido com ISSR por Almeida et al. (2009), para discriminar variedades comerciais de cana-de-açúcar. Esse resultado 
Tabela 2 - Total de bandas e polimorfismo gerados nas progênies de cana-de-açúcar por meio dos marcadores RAPD

\begin{tabular}{lcccc}
\hline Oligonucleotídeos & Total de bandas amplificadas & Bandas monomórficas & Bandas polimórficas & $(\%)$ \\
\hline OPAL 09 & 5 & 0 & 5 & 100 \\
OPAN 20 & 5 & 0 & 5 & 100 \\
OPAX 02 & 1 & 0 & 1 & 100 \\
OPAX 09 & 5 & 1 & 4 & 80 \\
OPAX 10 & 4 & 1 & 3 & 75 \\
OPAX 11 & 5 & 0 & 5 & 100 \\
OPAX 12 & 8 & 0 & 8 & 100 \\
OPAX 16 & 7 & 0 & 7 & 100 \\
OPAX 17 & 6 & 0 & 6 & 100 \\
OPAX 18 & 6 & 1 & 5 & 100 \\
OPAX 19 & 9 & 0 & 9 & 83,34 \\
\hline Total & 61 & 3 & 58 & 100 \\
\hline
\end{tabular}

é interessante porque demonstra que os marcadores RAPD, embora menos robustos que os ISSR, podem ser perfeitamente utilizados para discriminar genótipos a um custo mais baixo, desde que a espécie utilizada detenha variabilidade genética suficiente para gerar polimorfismo, como é o caso da cana-de-açúcar.

Esse resultado é importante, pois nos programas de melhoramento genético de cana-de-açúcar os cruzamentos geralmente são planejados levando em consideração o desempenho agronômico dos genitores nas fases mais avançadas de seleção e de experimentação. Para Tabasum et al. (2010), sucessivas seleções para as mesmas características pode levar ao estreitamento da base genética comprometendo a obtenção de genótipos superiores. Com este elevado nível de polimorfismo alcançado é possível discriminar genótipos a nível de DNA evitando os efeitos da endogamia por se tratar de uma espécie predominantemente alógama.
Os EST's SSR amplificaram um total de 38 alelos (Tabela 3), dos quais 34 foram polimórficos $(89,47 \%)$ e 4 foram monomórficos $(10,53 \%)$. O oligonucleotídeo mais polimórfico foi SCC04, que amplificou 8 alelos, todos com $100 \%$ de polimorfismo; o menos polimórfico foi SCB07, com cinco alelos, três polimórficos $(60 \%)$ e dois monomórficos (40\%).

Os marcadores EST's SSR utilizados neste trabalho detectaram um nível de polimorfismo genético maior do que os usados por Silva (2001), que também utilizou oligonucleotídeos EST's SSR para detectar polimorfismo genético em genótipos selvagens e híbridos comerciais de cana-de-açúcar. Para se alcançar maior produtividade na cana-de-açúcar é necessário manter um elevado grau de diversidade genética nas populações derivadas de cruzamentos previamente planejados na qual se praticará a seleção. Em se tratando de marcadores moleculares

Tabela 3 - Detecção de polimorfismo genético em populações de cana-de-açúcar obtido através de sete marcadores EST’s SSR

\begin{tabular}{lcccc}
\hline Oligonucleotídeos & Total de alelos amplificados & Alelos monomórficos & Alelos Polimórficos & $(\%)$ \\
\hline SCC01 & 4 & 0 & 4 & 100 \\
SCB07 & 5 & 2 & 3 & 60 \\
SCC04 & 8 & 0 & 8 & 100 \\
SCA07 & 5 & 0 & 5 & 100 \\
SCC05 & 5 & 0 & 5 & 100 \\
SCA08 & 7 & 1 & 6 & 85,71 \\
SCA10 & 3 & 1 & 2 & 66,67 \\
\hline Total & 38 & 4 & 34 & 89,47 \\
\hline
\end{tabular}


funcionais que estão ligados a locos que determinam caracteres de interesse, o alto grau de polimorfismo genético detectado pelos marcadores ETS's SSR no presente trabalho, contribuirão para a obtenção de novas populações com elevado potencial para a recuperação de novos genótipos de maior efeito heterótico e com caracteres de interesse à agroindústria canavieira nas fases subsequentes de seleção.

Os dados gerados por meio da AMOVA encontramse na Tabela 4. Observa-se que o percentual de variação genética foi muito semelhante para as duas classes de marcadores, sendo maior dentro das progênies $(87,75$ e $85,19 \%)$ do que entre elas (12,25 e $14,81 \%)$, para RAPD e EST's SSR, respectivamente.

A baixa porcentagem da variação genética detectada entre as populações (progênies oriundas das variedades $\mathrm{RB}$ ) é reflexo dos sucessivos ciclos de seleção e recombinação para desenvolvimento de novas variedades, porém mais homogêneas e com base genética mais estreita. Por outro lado, a maior porcentagem da variação genética detectada dentro das progênies reflete a ocorrência de maior variabilidade nas populações, contribuindo para o sucesso dos trabalhos de melhoramento.

Os valores da dissimilaridade genética entre os clones e variedades avaliados variaram de 0,22 a 0,77 (Tabela 5). A menor dissimilaridade foi registrada entre os clones UFRPE06-03 e UFRPE06-06 ambos provenientes da autofecundação da variedade RB867515. Em contrapartida, os clones UFRPE06-10 e UFRPE06-19 foram os mais distantes geneticamente, sendo estes, provenientes da autofecundação das variedades RB943365 e RB863129, respectivamente.

Considerando-se que as populações avaliadas foram obtidas por meio de autofecundação, para um trabalho de melhoramento, se estabeleceu como satisfatória as hibridações entre genótipos com dissimilaridade genética $\geq 0,70(70 \%)$. Assim, as combinações mais promissoras seriam entre os clones UFRPE06-13 x UFRPE06-20, UFRPE06-03 x UFRPE0610, UFRPE06-10 x UFRPE06-17, UFRPE06-10 $\mathrm{x}$ UFRPE06-18, UFRPE06-02 x UFRPE06-20, UFRPE06-05 x UFRPE06-10, UFRPE06-06 x UFRPE06-10 e UFRPE0610 x UFRPE06-19.

Quando se efetua cruzamentos entre indivíduos distantes geneticamente a tendência é de compartilharem muitos genes e alelos não comuns havendo complementariedade e alto vigor com maior probabilidade de manifestação da heterose (TABASUM et al., 2010).

O coeficiente de correlação cofenético entre a matriz de dissimilaridade obtida pelo complemento aritmético do coeficiente de Jaccard e a matriz cofenética foi de $r=0,91$. Isso indica a precisão entre os valores originais de dissimilaridade e os representados no dendrograma da Figura 1, o qual foi gerado pelo método UPGMA, com base nos padrões de bandas dos marcadores RAPD e EST's-SSR.

Com base no ponto de corte correspondente a dissimilaridade genética de aproximadamente $77 \%$, pode-se constatar a formação de 3 grandes grupos. O grupo I aglomerou os genótipos UFRPE06-03, UFRPE06-06, UFRPE06-02, UFRPE06-01, UFRPE0605, UFRPE06-04, RB943365, UFRPE06-07, RB863129, UFRPE06-14, UFRPE06-16, UFRPE0611, UFRPE06-15, UFRPE06-12, UFRPE06-13, RB867515, UFRPE06-17 e UFRPE06-18. O grupo II os genótipos UFRPE06-19 e UFRPE06-20 e o III os genótipos UFRPE06-08, UFRPE06-09 e UFRPE0610. A variedade comercial RB867515 apesar de estar inclusa no mesmo grupo das variedades RB943365

Tabela 4 - AMOVA para os genótipos de cana-de-açúcar com base na amplificação de marcadores RAPD (63 bandas) e EST's SSR (38 alelos)

\begin{tabular}{lccccc}
\hline Fonte de variação & GL & SQ & Variação total (\%) & ØST & P \\
\hline RAPD & & & & & 0,1225 \\
Entre progênies & 2 & 40,85 & 12,25 & 0,0001 \\
Dentro de progênies & 20 & 197,5 & 87,75 & 100 & 0,0001 \\
\hline Total & 22 & 238,35 & & & 0,1481 \\
\hline EST's SSR & 2 & 23,98 & 14,81 & \\
Entre progênies & 20 & 102,89 & 85,19 & & \\
Dentro de progênies & 22 & 126.87 & 100 & & \\
\hline Total & 22 & & & \\
\hline
\end{tabular}

Nota: G.L: Graus de liberdade; ØST: Estatística ST; S.Q: Soma de quadrados; P: Probabilidade (Nível de significância) 
Tabela 5 - Matriz de dissimilaridade, entre 23 genótipos de cana-de-açúcar, obtida através do complemento aritmético do coeficiente de Jaccard a partir de informações binárias geradas por marcadores moleculares RAPD e EST's SSR

\begin{tabular}{|c|c|c|c|c|c|c|c|c|c|c|c|c|}
\hline G & 1 & 2 & 3 & 4 & 5 & 6 & 7 & 8 & 9 & 10 & 11 & 12 \\
\hline 1. RB867515 & 0 & 0,36 & 0,36 & 0,42 & 0,43 & 0,52 & 0,48 & 0,43 & 0,48 & 0,49 & 0,56 & 0,55 \\
\hline 2. UFRPE06-01 & & 0 & 0,34 & 0,32 & 0,30 & 0,35 & 0,34 & 0,37 & 0,45 & 0,48 & 0,58 & 0,65 \\
\hline 3. UFRPE06-02 & & & 0 & 0,23 & 0,32 & 0,33 & 0,32 & 0,31 & 0,43 & 0,60 & 0,63 & 0,67 \\
\hline 4. UFRPE06-03 & & & & 0 & 0,32 & 0,33 & 0,22 & 0,36 & 0,38 & 0,65 & 0,63 & 0,70 \\
\hline 5. UFRPE06-04 & & & & & 0 & 0,41 & 0,43 & 0,43 & 0,45 & 0,59 & 0,61 & 0,63 \\
\hline 6. UFRPE06-05 & & & & & & 0 & 0,36 & 0,40 & 0,47 & 0,66 & 0,63 & 0,72 \\
\hline 7. UFRPE06-06 & & & & & & & 0 & 0,42 & 0,35 & 0,67 & 0,65 & 0,74 \\
\hline 8. RB943365 & & & & & & & & 0 & 0,36 & 0,58 & 0,55 & 0,64 \\
\hline 9. UFRPE06-07 & & & & & & & & & 0 & 0,59 & 0,55 & 0,63 \\
\hline 10. UFRPE06-08 & & & & & & & & & & 0 & 0,38 & 0,45 \\
\hline 11. UFRPE06-09 & & & & & & & & & & & 0 & 0,49 \\
\hline 12. UFRPE06-10 & & & & & & & & & & & & 0 \\
\hline \multicolumn{13}{|l|}{ 13. UFRPE06-11 } \\
\hline \multicolumn{13}{|l|}{ 14. UFRPE06-12 } \\
\hline \multicolumn{13}{|l|}{ 15. UFRPE06-13 } \\
\hline \multicolumn{13}{|l|}{ 16. RB863129 } \\
\hline \multicolumn{13}{|l|}{ 17. UFRPE06-14 } \\
\hline \multicolumn{13}{|l|}{ 18. UFRPE06-15 } \\
\hline \multicolumn{13}{|l|}{ 19. UFRPE06-16 } \\
\hline \multicolumn{13}{|l|}{ 20. UFRPE06-17 } \\
\hline \multicolumn{13}{|l|}{ 21. UFRPE06-18 } \\
\hline \multicolumn{13}{|l|}{ 22. UFRPE06-19 } \\
\hline \multicolumn{13}{|l|}{ 23. UFRPE06-20 } \\
\hline G & 13 & 14 & 15 & 16 & 17 & 18 & 19 & 20 & 21 & 22 & 23 & \\
\hline 1. RB867515 & 0,46 & 0,39 & 0,48 & 0,38 & 0,39 & 0,47 & 0,49 & 0,53 & 0,53 & 0,62 & 0,55 & \\
\hline 2. UFRPE06-01 & 0,37 & 0,41 & 0,41 & 0,37 & 0,49 & 0,47 & 0,39 & 0,46 & 0,54 & 0,63 & 0,59 & \\
\hline 3. UFRPE06-02 & 0,43 & 0,39 & 0,41 & 0,35 & 0,41 & 0,46 & 0,46 & 0,57 & 0,55 & 0,67 & 0,71 & \\
\hline 4. UFRPE06-03 & 0,41 & 0,38 & 0,38 & 0,36 & 0,44 & 0,44 & 0,45 & 0,49 & 0,47 & 0,65 & 0,63 & \\
\hline 5. UFRPE06-04 & 0,49 & 0,39 & 0,47 & 0,39 & 0,45 & 0,49 & 0,50 & 0,54 & 0,60 & 0,69 & 0,66 & \\
\hline 6. UFRPE06-05 & 0,32 & 0,42 & 0,38 & 0,39 & 0,46 & 0,39 & 0,43 & 0,49 & 0,45 & 0,69 & 0,67 & \\
\hline 7. UFRPE06-06 & 0,36 & 0,40 & 0,38 & 0,43 & 0,48 & 0,39 & 0,41 & 0,47 & 0,49 & 0,63 & 0,63 & \\
\hline 8. RB943365 & 0,38 & 0,36 & 0,36 & 0,34 & 0,45 & 0,47 & 0,34 & 0,48 & 0,50 & 0,69 & 0,68 & \\
\hline 9. UFRPE06-07 & 0,43 & 0,38 & 0,44 & 0,34 & 0,44 & 0,46 & 0,36 & 0,37 & 0,49 & 0,65 & 0,63 & \\
\hline 10. UFRPE06-08 & 0,58 & 0,58 & 0,65 & 0,50 & 0,54 & 0,62 & 0,58 & 0,56 & 0,60 & 0,62 & 0,48 & \\
\hline 11. UFRPE06-09 & 0,57 & 0,54 & 0,65 & 0,53 & 0,50 & 0,63 & 0,54 & 0,56 & 0,61 & 0,62 & 0,60 & \\
\hline 12. UFRPE06-10 & 0,66 & 0,63 & 0,69 & 0,58 & 0,58 & 0,68 & 0,64 & 0,71 & 0,71 & 0,77 & 0,69 & \\
\hline 13. UFRPE06-11 & 0 & 0,32 & 0,34 & 0,35 & 0,46 & 0,28 & 0,39 & 0,45 & 0,38 & 0,64 & 0,65 & \\
\hline 14. UFRPE06-12 & & 0 & 0,29 & 0,30 & 0,35 & 0,32 & 0,36 & 0,40 & 0,44 & 0,61 & 0,68 & \\
\hline 15. UFRPE06-13 & & & 0 & 0,31 & 0,37 & 0,32 & 0,36 & 0,49 & 0,45 & 0,65 & 0,70 & \\
\hline 16. RB863129 & & & & 0 & 0,26 & 0,30 & 0,29 & 0,43 & 0,45 & 0,68 & 0,65 & \\
\hline
\end{tabular}


Continuação da Tabela 5

\begin{tabular}{|c|c|c|c|c|c|c|c|}
\hline 17. UFRPE06-14 & 0 & 0,39 & 0,33 & 0,51 & 0,49 & 0,57 & 0,63 \\
\hline 18. UFRPE06-15 & & 0 & 0,40 & 0,44 & 0,44 & 0,67 & 0,65 \\
\hline 19. UFRPE06-16 & & & 0 & 0,35 & 0,41 & 0,59 & 0,64 \\
\hline 20. UFRPE06-17 & & & & & & & 0,52 \\
\hline 21. UFRPE06-18 & & & & & & & 0,55 \\
\hline 22. UFRPE06-19 & & & & & & & 0,43 \\
\hline 23. UFRPE06-20 & & & & & & & 0 \\
\hline
\end{tabular}

Figura 1 - Dendrograma representativo do padrão de dissimilaridade, estabelecido pelo método hierárquico da ligação média entre grupo, com base na utilização conjunta de marcadores moleculares do tipo RAPD e EST'S SSR. O valor do coeficiente de correlação cofenético (r) é de 0,91

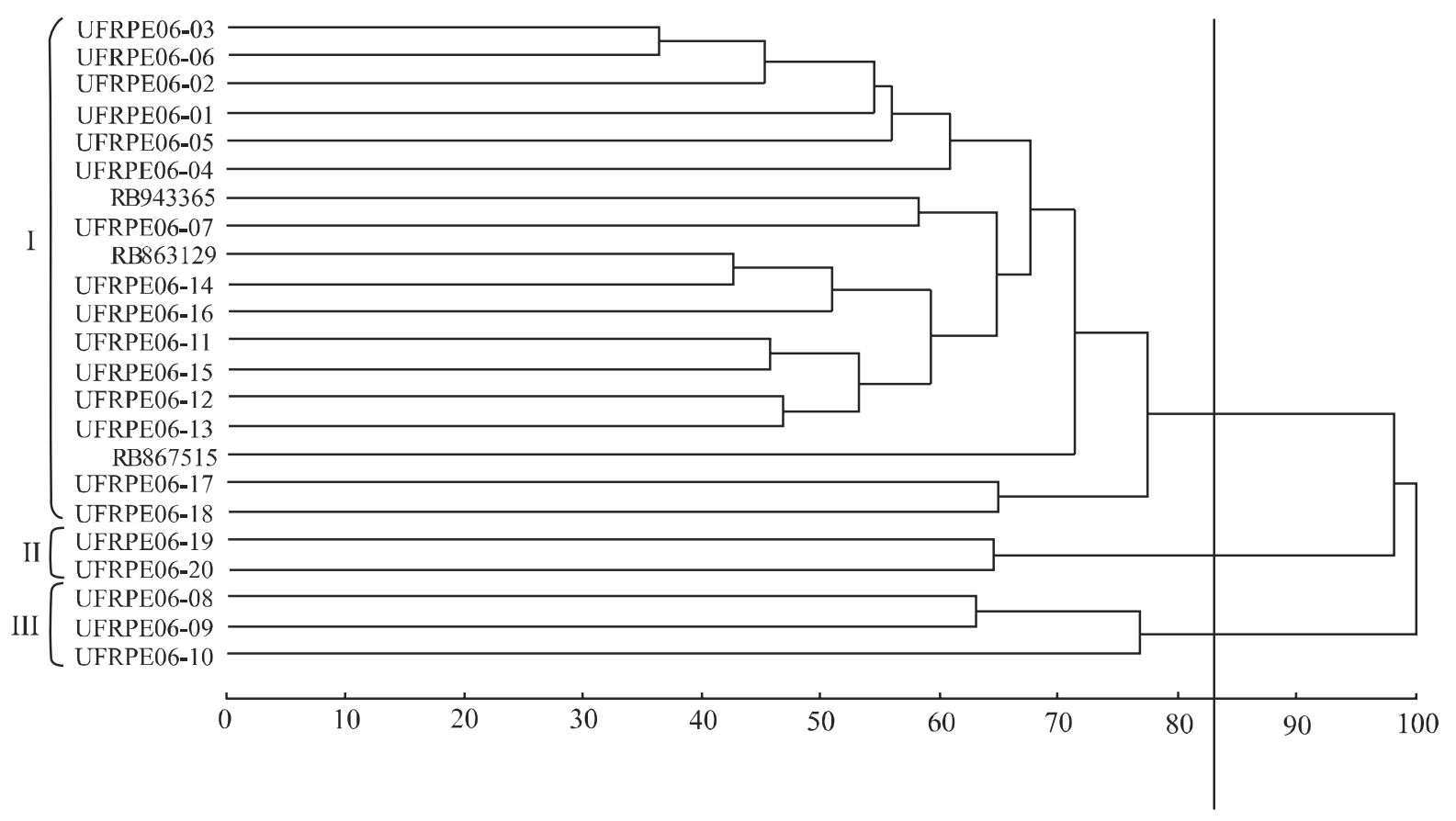

e RB863129, comportou-se como a mais distinta, isto pode ser devido também a grande diferença nos descritores morfológicos em relação a essas variedades apresentados na Tabela 1. Já as variedades RB943365 e RB863129 estão muito próximas e se assemelham quanto a seis descritores morfológicos, incluindo a resistência a ferrugem marrom e a escaldadura das folhas que são caracteres geralmente controlados por um ou poucos genes.

Constata-se ainda que os genótipos mais distantes geneticamente, e, portanto recomendados para hibridização foram alocados em grupos distintos no dendrograma e diferem quanto a um grande número de descritores morfológicos, a exemplo dos genótipos UFRPE06-13 x UFRPE06-20, UFRPE0603 x UFRPE06-10, UFRPE06-10 x UFRPE0617, UFRPE06-10 x UFRPE06-18, UFRPE06-02 $\mathrm{x}$ UFRPE06-20, UFRPE06-05 x UFRPE06-10, UFRPE0606 x UFRPE06-10 e UFRPE06-10 x UFRPE06-19. Revelando grande concordância entre os resultados expressos pela matriz de dissimilaridade e os grupos representados no dendrograma, além de alta eficiência dos marcadores RAPD e EST's SSR para acessar a variabilidade genética em cana-de-açúcar e discriminar genótipos para recombinações com perspectivas favoráveis na obtenção de populações melhoradas 
e recuperação de novos clones com caracteres de interesse nas fases subsequentes de seleção.

\section{CONCLUSÕES}

1. Os marcadores RAPD e EST's SRR são contributivos para discriminar genótipos de cana-de-açúcar oriundos de autofecundação;

2. Hibridações entre os genótipos UFRPE06-13 x UFRPE06-20, UFRPE06-03 x UFRPE06-10, UFRPE0610 x UFRPE06-17, UFRPE06-10 x UFRPE0618, UFRPE06-02 x UFRPE06-20, UFRPE06-05 $x$ UFRPE06-10, UFRPE06-06 x UFRPE06-10 e UFRPE06-10 x UFRPE06-19 devem ser exploradas visando à obtenção de populações melhoradas e de novos clones geneticamente superiores que venham a ser amplamente cultivados a nível comercial.

\section{REFERÊNCIAS}

ALMEIDA, C. M. A. et al. Caracterização molecular de cultivares de cana-de-açúcar utilizando marcadores ISSR. Ciência e Agrotecnologia, v. 33, p. 1771-1776, 2009. Edição Especial.

AMORIM, E. P.et al. Variabilidade genética estimada entre diplóides de banana por meio de marcadores microssatélites. Pesquisa Agropecuária Brasileira, v. 43, n. 08, p. $1045-$ 1052, 2008.

CAIXETA, E. T. et al. Tipos de Marcadores moleculares. In: CAIXETA, E. T.; BORÉM, A. Marcadores Moleculares. Viçosa: Editora UFV, 2006. cap. 1, p. 9-78.

COMPANHIA NACIONAL DE ABASTECIMENTO. Resultados da safra cana-de-açúcar no Brasil 2011/2012. Disponível em: http://www.conab.gov.br/conabweb/>. Acesso em: 2 abr. 2012.

CRUZ, C.D. Programa Genes: Biometria. Viçosa: Editora UFV, 2006. 382 p.

EXCOFFIER, L.; SMOUSE, P. E.; QUATTRO, J. M. Analysis of molecular variance inferred from metric distances among DNA haplotypes: application to human mitochondrial DNA restriction data. Genetics, v. 131, n. 02, p. 479-491, 1992.
FERREIRA, M. E.; GRATAPAGLIA, D. Introdução ao uso de marcadores moleculares em análise genética. 3. ed. Brasília: EMBRAPA-CENARGEN, 1998. 220 p.

FUGANTI, R. et al. Identificação de marcadores moleculares de microssatélites para seleção de genótipos de soja resistentes a Meloidogyne javanica. Nematologia Brasileira, v. 28, n. 02, p. 125-130, 2004.

LEAL, A. A. et al. Efficiency of RAPD versus SSR markers for determining genetic diversity among popcorn lines. Genetics and Molecular Research, v. 9, n. 01, p. 9-18, 2010.

MATSUOKA, S.; GARCIA, A. A. F.; ARIZONO, H. Melhoramento da cana-de-açúcar. In: BORÉM, A. Melhoramento de espécies cultivadas. Viçosa: UFV, 2005. cap. 7 , p. 225-274.

NIENHUIS, J. et al. Genetic relations among cultivars and lines of lima bean (Phaseolus lunatus L.) as measured by RAPD marker. Journal of the American Society for Horticultural Science, v. 120, n. 02, p. 300-306, 1995.

PINTO, L. R.et al. Survey in the sugarcane expressed sequence tag database (SUCEST) for simple sequence repeats. Genome, v. 47 , n. 05 , p. 795-804, 2004.

SALLA, M. F. S. et al. Uso de marcadores moleculares na análise da variabilidade genética em acerola (Malpighia emarginata d.c.). Revista Brasileira de Fruticultura, v. 24, n. 01, p. 015-022, 2002.

SHIMOYA, A. et al. Divergência genética entre acessos de um banco de germoplasma de capim-elefante. Pesquiza Agropecuária Brasileira, v. 37, n. 07, p. 971-980, 2002.

SILVA, J. A. G. Preliminary analysis of microsatellite markers derived from sugarcane expressed sequence tags (ESTs). Genetics and Molecular Biology, v. 24, n. 1/4, p. 155-159, 2001.

STUPIELlO, J. P. Conversando com a cana. STAB, v. 20, n. 05, p. $38,2002$.

SOKAL, R. R.; ROHLF, F. J. The comparison of dendrograms by objective methods. Taxonomy, v. 11, n. 02, p. 30-40, 1962.

TABASUM, S. et al. DNA profiling of sugarcane genotypes using randomly amplified polymorphic DNA. Genetics and Molecular Research, v. 9, n. 01, p. 471-483, 2010.

WUNSCH, A.; HORMAZA, J. I. Cultivar identification and genetic fingerprinting of temperate fruit tree species using DNA markers. Euphytica, v. 125, n. 01, p. 59-67, 2002. 